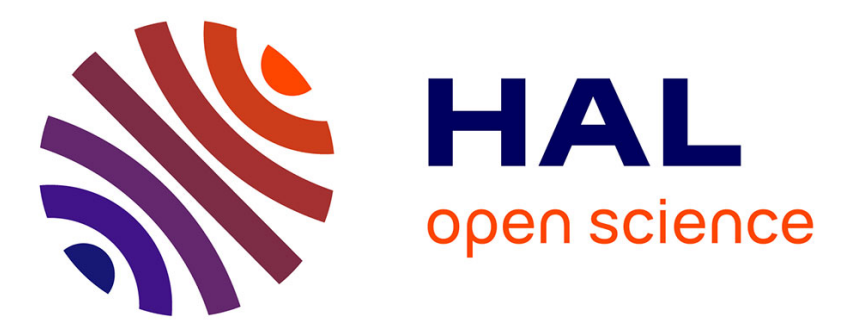

\title{
Quantum efficiency of energy transfer in noncovalent carbon nanotube/porphyrin compounds
}

Cyrielle Roquelet, Damien Garrot, Jean-sébastien Lauret, C. Voisin, Valérie Alain-Rizzo, Philippe Roussignol, Jacques A. Delaire, Emmanuelle Deleporte

\section{- To cite this version:}

Cyrielle Roquelet, Damien Garrot, Jean-sébastien Lauret, C. Voisin, Valérie Alain-Rizzo, et al.. Quantum efficiency of energy transfer in noncovalent carbon nanotube/porphyrin compounds. Applied Physics Letters, 2010, 97 (14), pp.141918. 10.1063/1.3496470 . hal-00528347

\section{HAL Id: hal-00528347 https://hal.science/hal-00528347}

Submitted on 21 Oct 2010

HAL is a multi-disciplinary open access archive for the deposit and dissemination of scientific research documents, whether they are published or not. The documents may come from teaching and research institutions in France or abroad, or from public or private research centers.
L'archive ouverte pluridisciplinaire HAL, est destinée au dépôt et à la diffusion de documents scientifiques de niveau recherche, publiés ou non, émanant des établissements d'enseignement et de recherche français ou étrangers, des laboratoires publics ou privés. 


\title{
Quantum efficiency of energy transfer in non-covalent carbon nanotube/porphyrin compounds
}

\author{
C. Roquelet,${ }^{1}$ D. Garrot,${ }^{1}$ J.S. Lauret, ${ }^{1, *}$ C. Voisin,${ }^{2}$ V. \\ Alain-Rizzo, ${ }^{3}$ Ph. Roussignol, ${ }^{2}$ J. A. Delaire,${ }^{3}$ and E. Deleporte ${ }^{1}$ \\ ${ }^{1}$ Laboratoire de Photonique Quantique et Moléculaire, \\ Institut d'Alembert, CNRS, ENS Cachan, 94235 Cachan, France \\ ${ }^{2}$ Laboratoire Pierre Aigrain, Ecole Normale Supérieure, \\ UPMC, Université Denis Diderot, CNRS, 75005 Paris, France \\ ${ }^{3}$ Laboratoire de Photophysique et Photochimie Supramoléculaires et Macromoléculaires, \\ Institut d'Alembert, CNRS, ENS Cachan, 94235 Cachan, France
}

(Dated: August 11, 2010)

\begin{abstract}
We report on the quantum yield of excitation energy transfer in non-covalently bound nanotube/porphyrin compounds. Evidence for energy transfer is gained from photoluminescence excitation experiments. We perform a quantitative evaluation of the transfer quantum yield in the case of $(6,5)$ nanotubes through three independent methods : quantitative PLE measurements, evaluation of the luminescence quenching of the donor (porphyrin) and ultrafast transient absorption measurements. The latter shows a tremendous increase of the porphyrin recovery rate upon incorporation in the compound. All these measurements consistently lead to an exceptional quantum yield efficiency: $1-10^{-3} \leq \eta \leq 1-10^{-5}$.
\end{abstract}

\footnotetext{
*Electronic address: lauret@lpqm.ens-cachan.fr
} 
Functionalization of single-wall carbon nanotubes (SWNTs) is a rapidly developing field in view of applications such as biology imaging [1] or optoelectronics [2-4]. In particular, the coupling of dye molecules with nanotubes is of great interest regarding possible photovoltaï and other optoelectronic applications $[2,3,5]$. The general motivation is to combine the exceptional transport properties of carbon nanotubes with the versatility of the optical properties of the chromophores. In this context, it is of particular importance to preserve the intrinsic properties of carbon nanotubes such as their high mobility. Therefore usual covalent chemistry, which leads to deep defects formation due to local destruction of the $\pi$-electronic system, should be avoided. In contrast, the use of non-covalent chemistry (such as $\pi$-stacking interaction) has proven to be compatible with high quality transport and optical properties of the nanotubes [6-8]. On the other hand it usually leads to poorly stable compounds [6-8]. Recently, an original method based on micelle encapsulation of the nanotube/molecule compound has been demonstrated that allows both stability and minimal perturbation to the nanotube properties [8]. Depending on the band alignment, this coupling can lead to either charge transfer (CT) or excitation energy transfer (EET). In view of applications, it is important to show that although the compound stability relies on weak interactions, it is possible to have an efficient coupling between the nanotube and the organic molecule.

In this Letter, we study SWNT/porphyrin compounds which are known for showing EET [6-8] and we perform a quantitative investigation of the strength of this coupling in the case of $(6,5)$ nanotubes by measuring the quantum yield and the dynamics of the energy transfer. Photoluminescence (PL) experiments conducted on carbon nanotube/porphyrin compounds show unambiguous evidence for EET : the emission of light on the near infra-red (NIR) transitions of the nanotube is strongly enhanced when the excitation is in resonance with absorption lines of the porphyrin molecule. Concomitantly, the fluorescence of the porphyrin is strongly suppressed. In the time domain, the complex shows a reduction by several orders of magnitude of the porphyrin ground state recovery time. Those three independent measurements consistently lead to an exceptional EET quantum yield comprised between $1-10^{-3}$ and $1-10^{-5}$.

Purified CoMoCAT nanotubes (SouthWest Nanotechnologies, SG65) containing mainly the $(6,5)$ chirality were functionalized with base-free tetraphenyl porphyrin (TPP) by means of the micelle swelling method (see [8] for details). The output of a monochromator illumi- 
nated by a UV-VIS Xenon lamp served as a tunable light source for the photoluminescence excitation experiments (PLE). A step of $10 \mathrm{~nm}$ is used for the excitation in the PLE map. The ultrafast pump/probe experiments were conducted in a degenerate configuration at $2.952 \mathrm{eV}$ and $2.831 \mathrm{eV}$ with a frequency doubled mode-locked Ti:Saphire laser which delivers $\sim 80$ fs pulses at a $86 \mathrm{MHz}$ repetition rate.

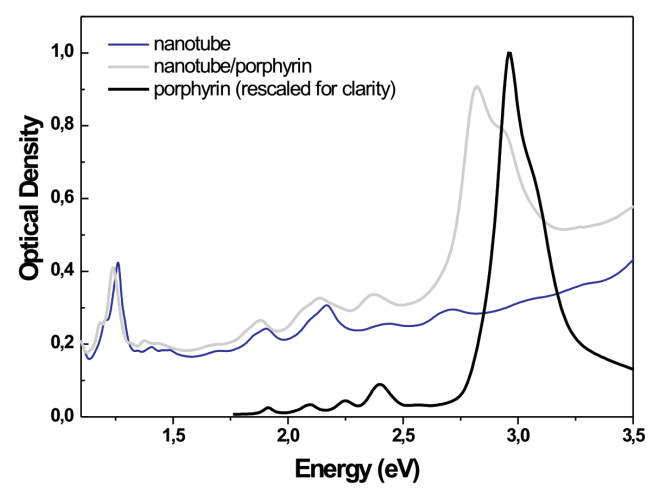

FIG. 1: Optical absorption spectra of a water suspension of nanotube in micelles (blue) and of a water suspension of nanotube/porphyrin compounds (grey). Optical absorption spectrum of a micellar suspension of porphyrins rescaled for clarity (black).

Carbon nanotubes display NIR absorption from $\mathrm{S}_{11}$ excitons (around $1.2 \mathrm{eV}$ ) and visible absorption from $\mathrm{S}_{22}$ excitons near $2 \mathrm{eV}$ (Figure 1, blue line). For the SWNT/TPP compounds (Figure 1, grey line), these lines are red-shifted of about $20 \mathrm{meV}$ as discussed in [6-8]. The main absorption line of the compound (the so-called Soret absorption band of the porphyrin) is observed at $2.831 \mathrm{eV}$. It corresponds to ground state absorption to the second electronic excited state of the porphyrin in the compound. The shoulder at $2.952 \mathrm{eV}$ is a signature of residual free porphyrins embedded in micelles (to be compared to free porphyrin absorption spectrum, black line in Fig. 1) [8]. The transitions to the first electronic excited states ( $\mathrm{Q}$ bands, around $2 \mathrm{eV}$ ) are barely visible in the compound since they are much weaker and further overlap with the $\mathrm{S}_{22}$ excitonic absorption of the nanotubes.

Figure 2a) displays the PLE map of the nanotube suspension. One spot predominates in this map. The semi-empirical formula of Bachilo et al. allows to assign this spot to 
the $(6,5)$ family [9]. Additional faint spots are present that correspond to weakly abundant chiral families. The PLE map of the nanotube/porphyrin compound suspension is shown in Figure $2 \mathrm{~b})$. The spot corresponding to $(6,5)$ nanotubes is red-shifted both in excitation and emission energies. This shift results from a dielectric screening of the excitonic transition by the porphyrin molecules [10]. Compared to the PLE map of nanotubes, additional spots are visible along the vertical dashed line for excitation energies of 2.805 and $2.357 \mathrm{eV}$. The spot at $(\mathrm{x}=1.240 \mathrm{eV}, \mathrm{y}=2.805 \mathrm{eV})$ corresponds to absorption on the Soret-band and emission by nanotubes. This brings evidence for excitation energy transfer from the porphyrin to the nanotube: when photons are absorbed by the porphyrin molecules, the luminescence of the nanotube is enhanced [6-8]. We assign the PLE feature at an excitation energy of $2.357 \mathrm{eV}$ to EET upon absorption on the porphyrin higher Q band, red shifted of about $50 \mathrm{meV}$ in comparison with free porphyrins. The other $\mathrm{Q}$ bands could not be evidenced in PLE measurements, most probably because of spectral overlap with the nanotubes $\mathrm{S}_{22}$ transitions. Nevertheless, the observation of the 2.357 eV PLE feature means that the EET occurs at least partially through the $\mathrm{Q}$ bands of the porphyrin molecules.
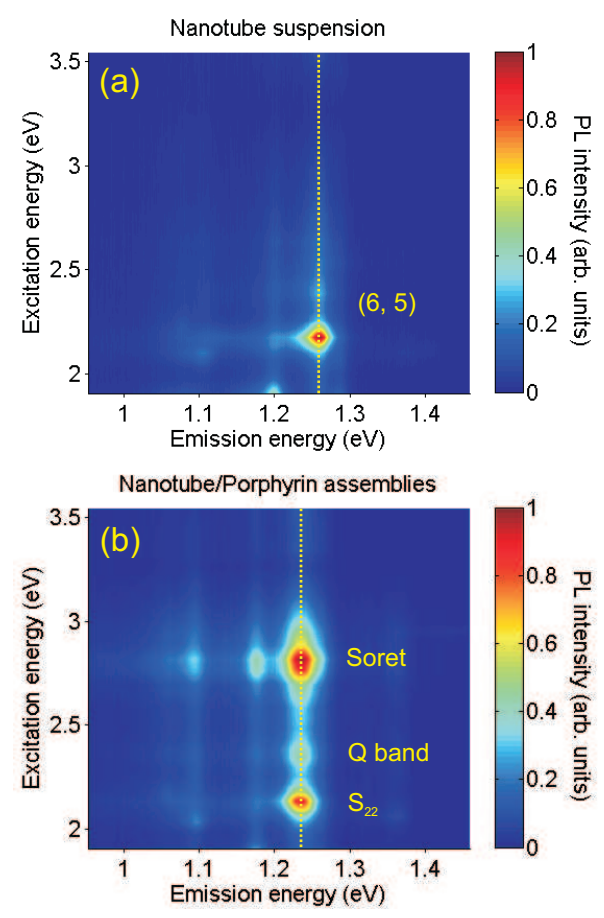

FIG. 2: PLE maps of a) the nanotube suspension; b) the nanotube/porphyrin compound suspension. The yellow dashed line corresponds to a PLE line-cut. 
Importantly, the intensity of the intrinsic PLE peak on the $S_{22}$ transition of $(6,5)$ nanotubes is on the same order than the PLE peak through EET from the Soret band (upper and lower peaks along the PLE line-cut in Fig. 2b). This allows quantitative investigation of the transfer yield. The PLE peak amplitude of nanotubes is related to their absorption cross-section $\sigma_{S_{22}}\left(1.1 \pm 0.1 \times 10^{-12} \mathrm{~cm}^{2} \cdot \mu \mathrm{m}^{-1}\right)$ for $(6,5)$ nanotubes [11], since it is well established that the internal conversion from $\mathrm{S}_{22}$ to $\mathrm{S}_{11}$ is ultrafast and efficient $[12,13]$. On the other hand, the PLE peak at $2.805 \mathrm{eV}$ (EET) is related to the absorption cross-section of the porphyrin $\left(\sigma_{T P P}=7 \times 10^{-16} \mathrm{~cm}^{2}\right)$ [14], the surface coverage of the nanotube by TPP molecules $(\alpha)$ and the transfer yield $(\eta)$. The equal amplitude of the two PLE peaks leads to the following relationship:

$$
\sigma_{T P P} \times N \times \eta=\sigma_{S_{22}} \text { with } N=\alpha \frac{S_{N T}}{S_{T P P}}
$$

where $\mathrm{S}_{T P P} \simeq 1.22 \mathrm{~nm}^{2}$ is the surface of one TPP molecule and $\mathrm{S}_{N T}$ is the wall surface per micron length of a $(6,5)$ nanotube. We find that $\eta \alpha=0.95 \pm 0.10$. The synthesis process ensuring that the coverage is close to one [8], we deduce that the transfer yield must also be on the order of one.

Another independent manner for evaluating this quantum efficiency is given by the quenching of the luminescence of the donor. Figure 3a) shows the visible luminescence of free porphyrins (black curve) and of the complex (grey curve) with the same porphyrin concentration and incident power. Both spectra display identical bands at $1.719 \mathrm{eV}$ and $1.900 \mathrm{eV}$ but the photoluminescence of the complex is reduced by a factor 750 for the complex. However, the position of the lines in the compound shows that the residual luminescence actually arises from left after porphyrin rather than from the compound itself since the bands of the latter should be red shifted by $\sim 50 \mathrm{meV}$. This assignment is further confirmed by PLE measurements: again the excitation spectrum of this residual PL (Figure 3b)) is identical to the one of free porphyrin whereas the redshift of the Soret band is of $120 \mathrm{meV}$ for the compounds (See Figure 1). When looking specifically for PL of the compound by tuning the excitation at $2,818 \mathrm{eV}$, we cannot detect any signal within our detectivity which is limited by the tail emission of free porphyrin. Assuming that any signal from the compound would be detected if of intensity comparable to this tail emission, we deduce $\frac{I_{d-a}}{I_{d}} \leq 9.10^{-4}$ where $\mathrm{I}_{d-a}$ (resp. $\mathrm{I}_{d}$ ) is the integrated PL intensity of the donor in presence (resp. absence) of the acceptor. Since the quantum efficiency of the EET process 

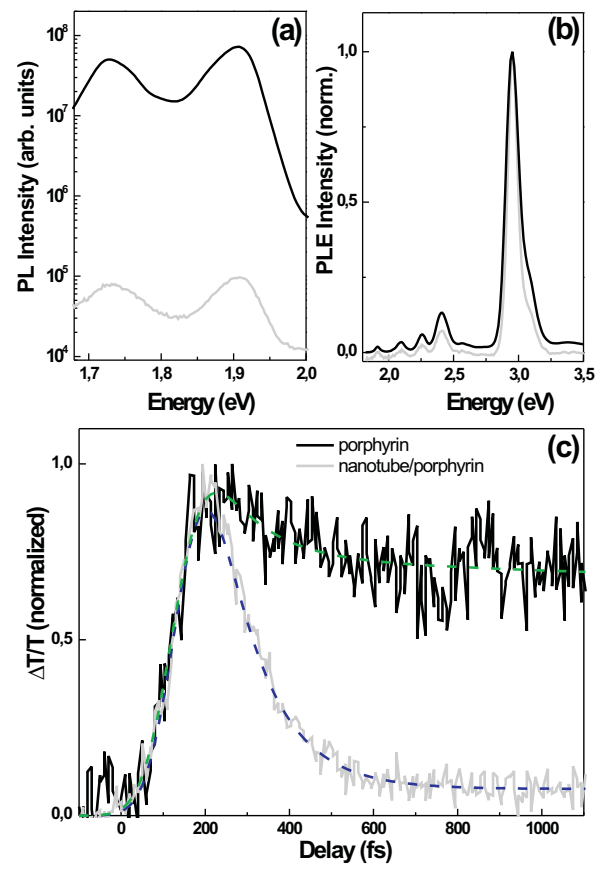

FIG. 3: a) Photoluminescence spectra of free porphyrins (black curve) and of the nanotube/porphyrin compounds (grey curve) excited on their respective Soret band. b) Normalized PLE detected 1.722 eV in free porphyrins (black curve) and in the nanotube/porphyrin compound (grey curve). c) Relative change of transmission as a function of the time delay for pump and probe in resonance with the Soret band of the free porphyrins (black curve) or in resonance with the Soret band of the compounds (grey curve). Green and blue dashed lines are bi-and mono-exponential fits respectively.

can be written:

$$
\eta=1-\frac{I_{d-a}}{I_{d}}
$$

we can give a lower bound of $\eta: \eta \geq 1-10^{-3}$.

Finally, ultrafast pump/probe experiments allowed us to gain further insight into the dynamics and therefore into the transfer yield of this EET. In these experiments, both pump and probe were tuned in resonance with the Soret band of the porphyrin (at $2.952 \mathrm{eV}$ for the free porphyrin or at $2.831 \mathrm{eV}$ for the compound). Free porphyrin shows a bi-exponential recovery dynamics (Figure 3c) with a main very slow component (unresolved here) that was reported to be on the order of 12 ns in previous studies [15]. This component corresponds 
to the ground state recovery. In nanotube/porphyrin compounds, this recovery time is dramatically reduced down to $\sim 120$ fs. This decrease of the donor life-time is typical of an efficient donor-acceptor coupling. The ratio $\frac{\tau_{d-a}}{\tau_{d}}$, where $\tau_{d}$ (resp. $\tau_{d-a}$ ) is the recovery time of the free (resp. in compound) porphyrin is on the order of $10^{-5}$ and is related to the efficiency $\eta$ by:

$$
\eta=1-\frac{\tau_{d-a}}{\tau_{d}}=1-10^{-5}
$$

In summary, we have reported on efficient and ultrafast excitation energy transfer in nanotube/porphyrin assemblies. The quenching of the porphyrin luminescence and the tremendous increase of its relaxation rate show that the efficiency of the EET process is very high. Cross-estimates of this quantum yield lead to $1-10^{-3} \leq \eta \leq 1-10^{-5}$. This result is especially strong for non-covalently bound compounds. This opens avenues for creating molecular assemblies based on nanotubes that preserve the nanotube intrinsic properties and nevertheless show efficient coupling to the chromophore for light-harvesting or photovoltaï applications.

This work was supported by the GDR-E "nanotube" (GDRE2756), grant "C'Nano IdF EPONAD" from "Région Ile de France" and ANR grant "CEDONA".

[1] Z. Liu, S. Tabakman, S. Sherlock, X. Li, Z. Chen, K. Jiang, S. Fan, and H. Dai, Nano Research 3, $222(2010)$.

[2] C. Ehli, C. Oelsner, D.M. Guldi, A. Mateo-Alonso, M. Prato, C. Schmidt, C. Backes, F. Hauke, A. Hirsch., Nature Chemistry 1, 243 (2009).

[3] S. Campidelli, B. Ballesteros, A. Filoramo, D. Daz Daz, G. de la Torre, T. Torres, G. M. Aminur Rahman, C. Ehli, D. Kiessling, F. Werner, V. Sgobba, D.M. Guldi, C. Cioffi, M. Prato, and J.P. Bourgoin, J. Am. Chem. Soc. 130, 11503 (2008).

[4] M. Alvaro, P. Atienzar, P. de la Cruz, J. L. Delgado, V. Troiani, H. Garcia, F. Langa, A. Palkar, and L. Echegoyen., J. Am. Chem. Soc. 128, 6626 (2006).

[5] C. Ehli, G. M. Aminur Rahman, N. Jux, D. Balbinot, D. M. Guldi, F. Paolucci, M. Marcaccio, D. Paolucci, M. Melle-Franco, F. Zerbetto, S. Campidelli, and M. Prato, J. Am. Chem. Soc. 128, $11222(2006)$. 
[6] G. Magadur, J.S. Lauret, V. Alain-Rizzo, C. Voisin, Ph. Roussignol, E. Deleporte, and J.A. Delaire., ChemPhysChem 9, 1250 (2008).

[7] J.P. Casey, S.M. Bachilo, and R.B. Weisman, Journal of Material Chemistry 18, 1510 (2008).

[8] C. Roquelet, J.S. Lauret, V. Alain-Rizzo, C. Voisin, R. Fleurier, M. Delarue, D. Garrot, A. Loiseau, Ph. Roussignol, J. A. Delaire, and E. Deleporte, ChemPhysChem 11, 1667 (2010).

[9] S.M. Bachilo, M.S. Strano, C. Kittrell, R.H. Hauge, R.E. Smalley, and R.B. Weisman., Science 298, $2361(2002)$.

[10] S. Berger, F. Iglesias, P. Bonnet, C. Voisin, G. Cassabois, J.S. Lauret, C. Delalande, and P. Roussignol, J. App. Phys. 105, 094323 (2009).

[11] S. Berciaud, L. Cognet and B. Lounis, Phys. Rev. Lett. 101, 077402 (2008).

[12] J.S. Lauret, C. Voisin, G. Cassabois, C. Delalande, Ph. Roussignol, L. Capes, O. Jost, Phys. Rev. Lett. 90, 057404 (2003).

[13] J. S. Lauret, C. Voisin, S. Berger, G. Cassabois, C. Delalande, Ph. Roussignol, L. Goux-Capes, A. Filoramo, Phys. Rev. B 72, 113413 (2005).

[14] J. B. Kim, J. J. Leonard and F. R. Longo, J. Am. Chem. Soc. 94, 3986 (1972).

[15] J. S. Baskin, H.Z. Yu and A. H. Zewail, J. Phys. Chem. A 106, 9837 (2002). 